\title{
Evaluation on the Effect of HTGN Treatments on the Corrosion Resistance and Magnetic Properties of Austenitic Stainless Steel 316L and 316LVM
}

\author{
Agus Suprihanto \\ Mechanical Engineering Department of Diponegoro University \\ JI. Prof. Sudharto, SH., Kampus UNDIP Tembalang, Semarang Jawa Tengah \\ E-mail: agus.suprihanto@ft.undip.ac.id
}

\begin{abstract}
High temperature gas nitriding (HTGN) is the new methods to enhance the properties of stainless steel. The HTGN process is able to diffuse the nitrogen atom into stainless steel. Increasing the nitrogen concentration produces higher corrosion resistance. Stainless steel for implant and medical devices such as 316L and 316LVM not only have to high corrosion resistance but also have to magnetic properties stabilities. Evaluation of corrosion and magnetic properties for austenitic stainless steel 316L and 316LVM after HTGN treatments was successfully done. The corrosion resistance not only significantly increases but the stability of austenite phase is also increases. Therefore HTGN treatments is suitable for improving the corrosion resistance for $316 L$ and $316 L V M$ which used as implant material.
\end{abstract}

Keywords: austenitic stainless steel 316L and 316LVM; HTGN treatments; implant material

\section{INTRODUCTION}

Austenitic stainless steel $316 \mathrm{~L}$ and $316 \mathrm{LVM}$ are ones of metallic biomaterial that widely used as implants and medical devices. They have high corrosion resistance and good mechanical properties. Corrosion resistance of metallic biomaterials can be used as the parameter of their biocompatibility. High corrosion resistance is more biocompatible. However, in the corrosive body fluid mediums, lack of oxygen and high load such as bone fixation the corrosion resistance of $316 \mathrm{~L}$ and $316 \mathrm{LVM}$ decrease. Corrosion products cause any adverse effects to the body [1].

Various surface treatments such as gas nitriding, ion implantation, and plasma nitriding have been successfully applied to enhance their corrosion resistance. These treatments usually have been conducted at low temperature or below the austenite temperature. Low temperature nitriding produces thin layer of expanded austenite phase which improve their hardness and corrosion resistant. This expanded austenite phase is ferromagnetic [2,3]. Furthermore this phase cause weakly ferromagnetic properties of nitride austenitic stainless steel.

Recently, increasing of corrosion resistance is not only concern for improvement of metallic biomaterial but also stable non-magnetic properties. The development magnetic resonance imaging (MRI) as clinical imaging tools needs metallic biomaterial that has stable non-magnetic properties. The principal issues for MR safety and compatibility are magnetically induced displacements and torque, radio frequency (RF) heating and image artifact [4]. Implanted and medical devices from austenitic stainless steel meet the MRI safety and compatibility in the up to $1.5 \mathrm{~T}$ systems. However the developments of new 3.0T MR system cause their MR compatibility being decrease $[5,6]$.

The improvement of corrosion resistance of austenitic stainless steel by low temperature nitriding which produce expanded austenite phase should be avoided due to the MR safety and compatibility issues. Another method which promises the improvement of corrosion resistance of austenitic stainless steel without produce expanded austenite 
phase or another ferromagnetic phase such as $(\mathrm{Fe}, \mathrm{Cr}, \mathrm{Mo}) \mathrm{N}$ is high temperature gas nitriding (HTGN) [7]. HTGN treatment is thermo chemical process which able to diffuse the nitrogen atom into stainless steel. Hardness and corrosion resistance significantly improve by this treatment.

The early work for elimination the magnetic properties using HTGN treatment has developed. Weakly magnetic properties of free nickel high nitrogen austenitic stainless steel due the present of delta ferrite can be eliminated by HTGN treatments [8]. Although HTGN treatment for stainless steel has been investigate by many researchers $[7,9,10]$ but the effect of HTGN treatments on the magnetic behavior of 316L and 316LVM not yet investigation. This papers deal with the effect of HTGN treatment on the corrosion and magnetic properties of $316 \mathrm{~L}$ and $316 \mathrm{LVM}$.

\section{Methodology}

Specimens were prepared from $316 \mathrm{~L}$ and $316 \mathrm{LVM}$ plate. The chemical compositions of the specimens are shown in table 1. Specimens were rinsed using ultrasonic cleaner in acetone as soaking medium prior HTGN treatments in order to remove oil and debris. HTGN treatments were carried out at modified three zone heating chamber of vertical

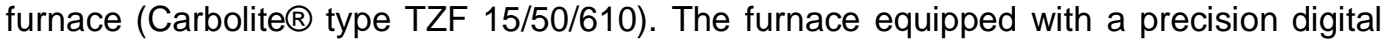
pressure controller in order to maintain the pressure in the tube during treatments.

Table 2.1 Chemical composition of specimens (\%wt)

\begin{tabular}{cccccccc}
\hline & $\mathbf{C}$ & $\mathbf{C r}$ & $\mathbf{N i}$ & Mo & Mn & Si & Fe \\
\hline 316L & 0.01 & 15.5 & 11.8 & 1.24 & 1.23 & 0.47 & balance \\
316LVM & 0.01 & 17.3 & 15.5 & 1.73 & 1.67 & 0.42 & balance \\
\hline
\end{tabular}

Specimens were inserted to the furnace tube, vacuumed to $10 \mathrm{~Pa}$ for 15 minute then flushed using nitrogen gas at $1000 \mathrm{ml} / \mathrm{min}$ for 15 minute prior heated. Nitrogen gas flowed continuously at $100 \mathrm{ml} / \mathrm{min}$ until treatment temperatures achieved. During process, the pressure inside the furnace tube maintained at 0,3atm. The temperature treatment was chosen at $1050{ }^{\circ} \mathrm{C}$ and holding time for 15 minutes. This temperature and holding time were selected as optimum process variables resulted from previous experiments [11, 12]. After heating process, specimen was quenched in the water.

As received and treated specimens were cut and machined to produce $1.4 \mathrm{~mm}$ disc. The discs were gently polished in order to remove the scale using metal polish. These discs produced $1 \mathrm{~cm}^{2}$ area in the corrosion test. The discs were rinsed by acetone prior corrosion test. The corrosion test was carried out at the surface of disc using polarizations resistance corrosion techniques in ringer solution as corrosion medium at temperature $37^{\circ} \mathrm{C}$. For the first running test, the initial potential test and final was selected $-20 \mathrm{mV}$ vs $E_{\text {corr }}$ and $+20 \mathrm{mV}$ vs SCE respectively and the potential scan rate was $0.1 \mathrm{mV}$. Each specimen tested for three times to determined $I_{\text {corr. }}$.

Magnetic properties were evaluated using vibrating sample magnetometer (VSM). As received and treated specimens processed in to powder using low speed saw before test. VSM test conducted by means exposure the powder in the magnetic field from -1 to $1 \mathrm{~T}$. Magnetic moment (emu) recorded during VSM test.

After HTGN treatments, treated specimens 316L and 316LVM were evaluated by XRD. The XRD test conducted at Shimadzu type 7000s. Scan range was chosen at $10-$ $90^{\circ}$ and scan speed 2 degree/min. XRD spectrum compared with crystallography open database (COD).

\section{RESULT and Discussion}

Figure 3.1 shows the polarization curve obtained from corrosion test. Polarization curve for treated specimen both $316 \mathrm{~L}$ and $316 \mathrm{LVM}$ are shift to up and left. It indicates that treated specimen has more corrosion resistance than as-received ones. Corrosion resistance of as received 316LVM is higher than as-received 316L. However, the 
corrosion resistance for treated specimen of $316 \mathrm{~L}$ is close to the as received $316 \mathrm{LVM}$. It indicates that HTGN treatment is able to enhance the corrosion resistance of $316 \mathrm{~L}$.

Table 3.1 show the $E_{\text {corr }}$ and $i_{\text {corr }}$ for as-received and treated specimens. Corrosion resistance of as received $316 \mathrm{~L}$ increases from $0.0228 \mathrm{mpy}$ up to $0.0011 \mathrm{mpy}$ after HTGN treatment. Corrosion resistance of as received 316LVM increases from 0.0013 up to $0.0002 \mathrm{mpy}$ after treatments. The increasing of corrosion resistance produced by HTGN treatments of $316 \mathrm{~L}$ is higher than for $316 \mathrm{LVM}$. HTGN treatment for $316 \mathrm{~L}$ is more effective to increasing the corrosion resistance than $316 \mathrm{LVM}$.

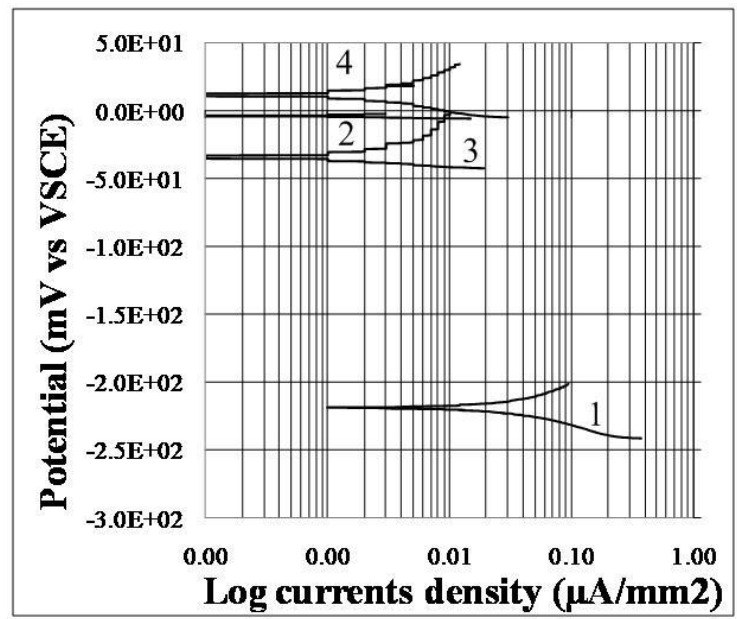

Figure 3.1 Polarization curve of as-received and treated specimens 1: as-received 316L, 2: treated 316L, 3: as-received 316LVM \& 4: treated 316LVM

Table 3.1 Potential corrosion and $i_{\text {corr }}$ of 316L and 316LVM

\begin{tabular}{ccccc}
\hline \multicolumn{2}{c}{ Specimens } & $\mathrm{E}_{\text {corr }}(\mathrm{mV})$ & $\mathrm{i}_{\text {corr }}\left(\mu \mathrm{A} / \mathrm{cm}^{2}\right)$ & Corrosion rate $(\mathrm{mpy})$ \\
\hline \multirow{2}{*}{$316 \mathrm{~L}$} & As-received & -218.46 & 0.06 & 0.0228 \\
& Treated & -119.48 & 0.00040 & 0.0011 \\
\multirow{3}{*}{ 16LVM } & As-received & -33.43 & 0.00041 & 0.0013 \\
& Treated & -39.11 & 0.00006 & 0.0002 \\
\hline
\end{tabular}

The corrosion resistance of stainless steels may predicted by pitting resistance equivalent number (PREN). The magnitude of PREN only depends on the chemical composition of stainless steel mainly for $\mathrm{Cr}$, Mo and $\mathrm{N}$. The corrosion resistance increase with PREN. The formulae of PREN is $\% \mathrm{Cr}+3,3 \times \% \mathrm{Mo}+(20-30) \% \mathrm{~N}$. However, the corrosion resistance of stainless steel actually not only depends on the chemical composition but also the cleanliness and homogeneity of their micro structure. Corrosion resistance increases with cleanliness and homogeneity.

The chemical composition of $316 \mathrm{~L}$ and $316 \mathrm{LVM}$ is not significantly different. There for the magnitude of PREN is also identically. Although the magnitude of PREN for $316 \mathrm{~L}$ and $316 \mathrm{LVM}$ is not significantly different, the corrosion resistance of as received 316LVM is higher than as received $316 \mathrm{~L}$. Type $316 \mathrm{LVM}$ is produced by remelting $316 \mathrm{~L}$ in the vacuum environment. The vacuum casting process produces micro structures which increase cleanliness and homogeneity $[13,14]$. Segregation and impurity are significantly reduced and lead to higher corrosion resistance.

Treated 316LVM has corrosion resistance close to the as-received $316 \mathrm{LVM}$ as indicate that polarization curve is close each other. Corrosion process do at the surface, there for the increasing corrosion resistance depends on the chemical composition at the surface. HTGN treatments increase the nitrogen contents. The diffusion process starts at the surface and become take place at the depth region. The magnitude of PREN at the surface increase with nitrogen contents at the surface. Increasing nitrogen contents at the surface cause the increasing corrosion resistance of the specimens. 
Figure 3.2 shows the magnetization curve from VSM test. As received 316LVM has magnetization curve is lower compared to the as-received 316L. It indicates that vacuums melting not only enhance the corrosion resistance but also improve the non-magnetic properties of $316 \mathrm{LVM}$. Non-magnetic properties of austenitic stainless steel increase with cleanliness and homogeneity.

Non-magnetic properties of $316 \mathrm{~L}$ and $316 \mathrm{LVM}$ are resulted from austenite phase. In the $\mathrm{Fe}-\mathrm{C}$ alloys, austenite phase is only present at high temperature. The addition of austenite stabilizer elements such as $\mathrm{Ni}, \mathrm{Mn}$ and $\mathrm{N}$ are caused the austenite phase stable until room temperature. However, this phase may transform into martensite phase if excessive cold working being applied. Martensite phase has strong ferromagnetic properties. The present of martensite phase at the austenitic stainless steel change the non-magnetic into weak magnetic properties. As received specimens are from plate which has been cold rolled during production. Martensite phase may present at the asreceived specimens that posse weak magnetic properties. Heat treatments at the proper temperature can eliminate the martensite phase.

The present of the other phase in austenitic stainless steel such as ( $\mathrm{Fe}, \mathrm{Cr}, \mathrm{Mo}) \mathrm{N}$ compound has the same effect on the magnetism properties with martensite phase. Increasing nitrogen contents after HTGN treatment may produce that alloys. A proper selected variable process eliminate the present of these compounds [7].

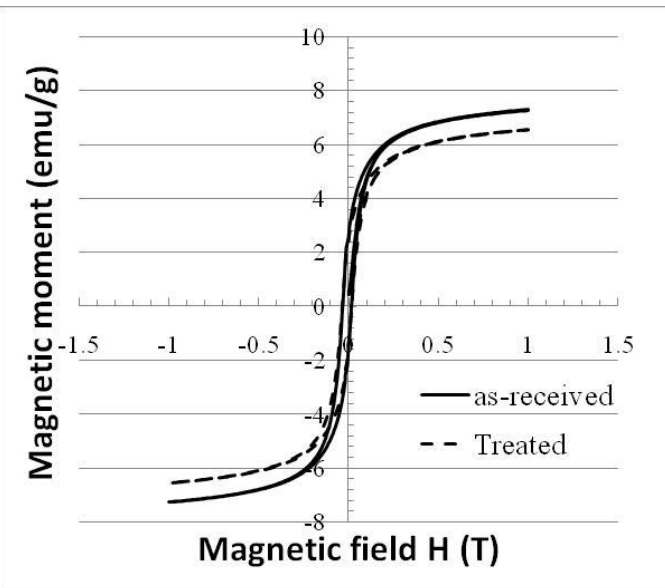

a. $316 \mathrm{~L}$

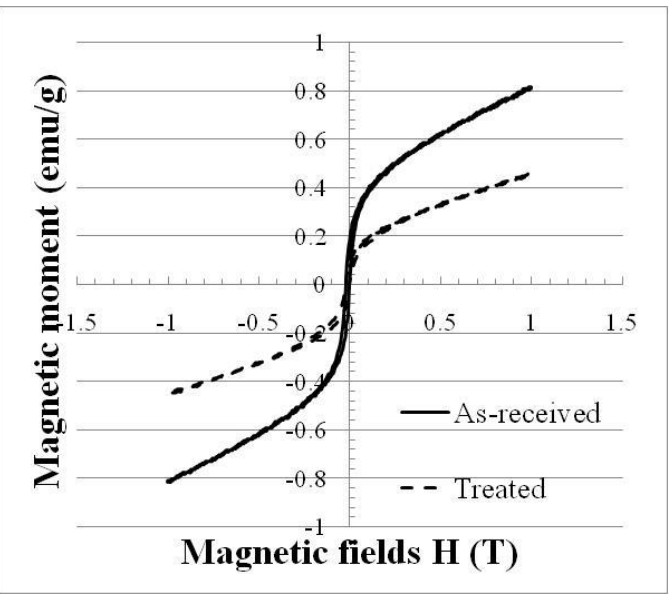

b. 316LVM

Figure 3.2 Magnetization curve of specimens

Magnetization curve both treated specimens for $316 \mathrm{~L}$ and $31 \mathrm{LVM}$ shows reduced the magnetic moments. It indicate that HTGN treatment not only increase the corrosion resistance but also improve the non-magnetic properties. However, the improving of nonmagnetic properties of $316 \mathrm{LVM}$ is higher than $316 \mathrm{~L}$. This phenomenon can be explained by dissolved magnetic phase during treatments and $(\mathrm{Fe}, \mathrm{Cr}, \mathrm{Mo}) \mathrm{N}$ are not produced during treatments.

The temperature of HTGN treatment is at the austenite temperature. In this temperature the only phase is austenite, the other phase such as martensite phase that may presents at room temperature dissolve during heating. Quenching process at the end of treatments produces austenite phase until room temperature.

The treatments does not produce the formation of $(\mathrm{Fe}, \mathrm{Cr}, \mathrm{Mo}) \mathrm{N}$ compounds as indicate from XRD spectrum at Fig. 3 which may presents due to the increasing the nitrogen contents. Increasing nitrogen contents is limited to the solubility of austenite phase. After solubility limit is achieved, nitrogen cannot continue to diffuse to the stainless steel. Diffusion process starts at the surface of specimens. The nitrogen contents at the surface may reach the limited solubility immediately. Longer holding time will produce diffusion more depth. So, the short holding time is enough to increase the nitrogen contents at the surface. It results higher corrosion resistance than as received specimens. 
The solubility limit of nitrogen cause the formation of $(\mathrm{Fe}, \mathrm{Cr}, \mathrm{Mo}) \mathrm{N}$ cannot be obtained by HTGN treatments for austenitic stainless steel.

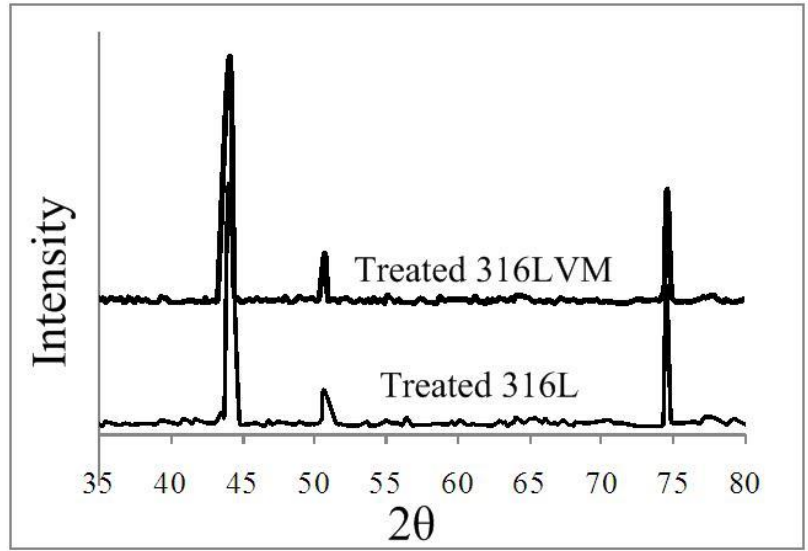

Figure 3.3 XRD spectrum specimens after HTGN treatments

\section{CONCLUSION}

HTGN treatments for austenitic stainless steel 316 and 316LVM at treatments temperature $1050{ }^{\circ} \mathrm{C}$ for 15 minutes enhanced both corrosion resistance and nonmagnetic properties. The improving non-magnetic properties after treatments because HTGN can dissolve the magnetic phase and does not produces $(\mathrm{Fe}, \mathrm{Cr}, \mathrm{Mo}) \mathrm{N}$ compounds. The enhancing of corrosion resistance and non-magnetic properties indicates that treated specimens are more biocompatible and MR safe than as-received samples.

\section{REFERENCES}

[1] Geetha, M., Durgalakshmi, D., Asokami, R., 2010, Biomedical Implants: Corrosion and Its Prevention-A Review, Recents Patents on Corrosion Science, 2, 40-54

[2] Menendez, E., Martinavicius, A., Liedke, MO., Abrasonis, G., Fassbender, J., Sommerlatte, J., Nielsch, K., Surinach, S., Baro, MD., Nogues J., Sort, J., 2008, Patterning of Magnetic Structure on Austenitic Stainless Steel by Local Ion Beam Nitriding, Acta Materialia, 56, pp. 4570-4576

[3] Basso, RLO., Pimentel, VL., Weber, S., Marcos, G., Czerwiec, T., Baumvol, IJR., Figueroa, CA., 2009, Magnetic and Structural Properties of Ion Nitrided Stainless Steel, Journal of Applied Physic, 105, pp. 124914-1-5

[4] Terry., OW., 2003, MRI Safety and Compatibility of Implants and Medical Devices, Stainless Steels for Medical and Surgical Applications, ASTM STP 1438, Winters, GL. \& Nutt, MJ., Eds., ASTM International, West Conshohocken, PA

[5] Shellock, FG., 2002, Biomedical Implants and Devices: Assessment of Magnetic Field Interactions with a 3.0 Tesla MR Systems, Journal of Magnetic Resonance Imaging, 16, pp. 721-732

[6] Holton, A., Walsh, E., Anayiotos, A., Pohost, G., Venugopalan, R., 2002, Comparative MRI Compatibility of 316L Stanless Steel Alloy and Nickel-Titanium Alloy Stents, Journal of Cardiovascular Magnetic Resonance, 4(4), pp. 423-430

[7] Berns, H., Siebert S., 1996, High nitrogen cases in stainless steel. ISIJ International, Volume 36, No. 7, pp: 927-931 
[8] Wan, P., Ren, Y., Zhang, B., Yang, K., 2011, Analysis of Magnetism in High Nitrogen Austenitic Stainless steel and Its Elimination by High Temperature Gas Nitriding, Journal of Material Science and Technology, 27(12), 1139-1142

[9] Mitsui, H., Kurihana, S., 2007, Solution Nitriding Treatment of Fe-Cr Alloys under Pressurized Nitrogen Gas, ISIJ International, 47(3): 479-485

[10] Sung, J.H., Kong, J.H., Yoo, D.K., On, H.Y., Lee, D.J., Lee, H.W., 2008, Phase Changes of the AISI 430 ferritic Stainless Steel after High Temperature Gas Nitriding and Tempering Heat Treatment, Material Science and Engineering A, Volume 489, pp.: 38-43

[11] Suprihanto A, Suyitno, Soekrisno R., Dharmastiti R., 2013, Corrosion resistance AISI $316 \mathrm{~L}$ after short holding time high temperature gas nitriding, Chemistry and material research, Volume 2, No 2, pp.: 1-7

[12] Soekrisno, R., Suyitno, Dharmastiti, R., Suprihanto, A., Corrosion Behavior of Austenitic Stainless Steel 316L and 316LVM After High Temperature Gas Nitriding, Journal of Chemical and Pharmaceutical Research, vol.7, No. 6, pp. 850-854

[13] Ahmadi, S., Arabi, H., Shokuhfar, A., Rezer, A., 2009, Journal of Materials Sciences and Technology., 25(5); 592-596

[14] Talha, M., Behera, CK., Sinha, OP., 2012, Journal of Chemical and Pharmaceutical Research, 4(1); 203-208 